\title{
Phytochemical Analysis and Antimicrobial/Antioxidant Activity of Cynodon dactylon (L.) Pers. Rhizome Methanolic Extract
}

\author{
Samira Savadi, ${ }^{1}$ Mohsen Vazifedoost $\mathbb{D},{ }^{1}$ Zohre Didar, ${ }^{1}$ Mohammad Mahdi Nematshahi, ${ }^{2}$ \\ and Eisa Jahed ${ }^{3}$ \\ ${ }^{1}$ Department of Food Science and Technology, Neyshabur Branch, Islamic Azad University, Neyshabur, Iran \\ ${ }^{2}$ Department of Food Science and Technology \& Young Researchers and Elite Club, Sabzevar Branch, Islamic Azad University, \\ Sabzevar, Iran \\ ${ }^{3}$ Department of Food Science and Technology, Urmia University, Urmia, Iran
}

Correspondence should be addressed to Mohsen Vazifedoost; m.vazifedoost@iau-neyshabur.ac.ir

Received 3 December 2019; Revised 27 January 2020; Accepted 5 March 2020; Published 1 April 2020

Academic Editor: Jorge Barros-Velázquez

Copyright $\odot 2020$ Samira Savadi et al. This is an open access article distributed under the Creative Commons Attribution License, which permits unrestricted use, distribution, and reproduction in any medium, provided the original work is properly cited.

A proper use of medicinal plants requires accurate scientific information and understanding of their chemical constituents. The therapeutic effects in the plants are due to the chemical compounds therein. Cynodon dactylon (L.) Pers. of the family Poaceae is a perennial, pan-tropical species of grass which is a well-known traditional medicine and has a renowned position for treatment of many symptoms and diseases. The chemical composition, free radical scavenging activity, and antimicrobial properties of the methanolic extract of $C$. dactylon rhizomes against selected bacterial and fungal strains were investigated using disk-diffusion method. The results indicated that the major fatty acid structures of $C$. dactylon methanolic extract were palmitic acid (36.40\%), oleic acid (28.26\%), and linoleic acid (17.01\%). Alpha-tocopherol (151.39 mg. kg $\left.{ }^{-1}\right)$ and sitosterol $\left(3199.62 \mathrm{mg} \cdot \mathrm{kg}^{-1}\right)$ were the main tocopherols and sterols, respectively. According to the instrumental analysis, the total phenolic compounds of methanolic extract were equal to $917.08 \mathrm{mg} \cdot \mathrm{kg}^{-1}$ and the main compound was hydroquinone (66.89\%). Antioxidant activity of the methanolic extract at concentrations of $100-1000 \mathrm{ppm}$ was $9.81-67.87 \%$, which is significantly different from the 200 ppm synthetic antioxidant (BHT) with free radical scavenging activity equal to $48.93 \%(p<0.05)$. The antimicrobial study revealed that the methanolic extract of C. dactylon rhizomes was effective against all of the bacterial pathogens and the antibacterial activity increased with an increase in the concentration of extract. Therefore, the largest zone of inhibition was observed against Bacillus cereus $(18.3 \pm 0.4 \mathrm{~mm})$ and Escherichia coli $(16.8 \pm 0.5 \mathrm{~mm})$ at $1000 \mathrm{ppm}$. The highest resistance was observed with Pseudomonas aeruginosa (inhibition zone of $12.8 \pm 0.15 \mathrm{~mm}$ ). Methanolic extract at $200 \mathrm{ppm}$ had no effect against fungus Aspergillus niger. However, at $1000 \mathrm{ppm}$ concentration, an inhibition zone with a diameter of $14.4 \pm 0.45 \mathrm{~mm}$ was formed.

\section{Introduction}

Medicinal plants play a very important role in the development of alternative drugs without the adverse effects of the synthetic drugs [1]. Plants and natural products form the basis of both modern and traditional medicines and nowadays they are widely used in the production of commercially produced drugs. Scientific and reliable reports indicated that about $25 \%$ of prescribed medicines worldwide are taken from herbs [2]. Plant essential oils, extracts, and various kinds of secondary metabolites are known as substances with antimicrobial and antioxidant properties with little or no toxic effects, which are vital in the management of many diseases [2, 3]. Actually, secondary metabolites with tremendous biological potential, known as phytochemicals, are ubiquitously present in plants and now are used as the mainstay of drug development [4].

As reported in the literature, according to an estimation of the WHO, about 80 percent of the world's population in Latin America, Africa, Asia, and the Middle East in 
particular, relies on herbs for its primary healthcare needs [5]. These herbs have minimal side effects and recently millions of dollars have been invested in pharmaceutical plants by pharmaceutical companies in order to produce natural medicines extracted from herbs $[5,6]$. The main reasons for using medicinal herbs are as follows: (i) they correspond more closely to the patient's ideology, (ii) they reduce concerns about the side effects of synthetic medicines, (iii) they are more affordable, (iv) they satisfy a desire for more personalized health care, and (v) they also allow more people's access to health information [2].

A substantial body of the literature has reported the multitude pharmacological applications of plant extracts and the compounds isolated from plant extracts [7]. Harnessing the biological potential of medicinal plants represents a sterling opportunity for the development of novel therapeutic candidates $[8,9]$. The bioactive plant extracts are a promising source of many drugs. For example, berberine (Berberis) and Quinine (Cinchona) are the antibiotics obtained from plants, which are highly effective against bacteria (Escherichia coli and Staphylococcus aureus) [10]. Thanks to the climate diversity, a vast diversity of wild bioactive plants is found in Iran. Therefore, it is possible to obtain herbal extracts in large quantities on industrial scale.

Cynodon dactylon (family: Poaceae) commonly known as dhub, doob, or harialil; other common names include durba (Bengali), garikoihallu (Kanarese), garikagaddi (Telugu), durua or haritali (Sanskrit), dhubkhabbal (Punjabi), durua (Marathi), and arugampul (Tamil). C. dactylon (L.) Pers. is a weed plant found in many regions such as East Africa, Asia, Australia, and Southern Europe [10]. It is a perennial grass which is used as forage, as medicinal plant, and for desert greening. The roots grow quickly leading to the rapid spread of C. dactylon (L.) Pers. It is mostly found in cereal fields, farms, road shoulders, and green spaces and parks. The plant is propagated through seeds and rhizomes. When crop seeds germinate and plants are established in the field, rhizomes of C. dactylon (L.) Pers. can grow in hard soils between roots of other crop plants to produce new plants [11]. Photochemical analyses have shown that $C$. dactylon (L.) Pers. contains flavonoids, alkaloids, glycosides, terpenoids, triterpenoid esters, saponins, tannins, resins, phytosterols, reducing sugars, carbohydrates, proteins, volatile oils, and fixed oils $[6,12]$. According to Unani system of medicine, $C$. dactylon has a sharp and hot taste with a good odor. The aerial parts and rhizomes of the plant have cardioprotective action and antibacterial, antimicrobial, antioxidant, wound-healing, antidiabetic, and diuretic effects $[10,13]$.

C. dactylon is used by traditional healers for purifying the blood, diarrhea, gonorrhea, conjunctivitis, anuria, biliousness, itches, and stomach ache [11]. The literature survey also reveals that the dried extracts of $C$. dactylon aerial parts were investigated for CNS activities in rat [5]. Other essential functions of this plant include analgesic and antipyretic, antiulcer, antihypertensive, antihysteric, antipyretic, antibiotic, antikidney stone, antiviral, antipsychotic, antigonorrheal infection as well as hypoglycemic agent $[11,14,15]$. Studies on lab animals have shown that methanolic extract of $C$. dactylon decreases the level of lipid peroxides. It was also revealed that the methanolic extract of $C$. dactylon had an antioxidant effect on COLO 320 DM cells, a colon cancer cell line, and the levels of antioxidant enzymes [6].

Few studies have been conducted on medicinal and antimicrobial properties of $C$. dactylon (L.) Pers. [10, 13-15], and further studies must be carried out to confirm its antioxidant and antimicrobial properties. Chemical constituents of the methanolic extract of the rhizomes of $C$. dactylon (L.) Pers. native to Iran were identified in this study for the first time and its antioxidant and antimicrobial properties were investigated.

\section{Materials and Methods}

2.1. Materials. A sufficient amount of $C$. dactylon rhizomes was collected from Mashhad, Iran. The extraneous parts were removed and the rhizomes were washed, immediately dried, and ground. Lyophilized ampoules containing standard strains of $P$. aeruginosa, E. coli, B. cereus, A. niger, and $S$. epidermidis were obtained from the Regional Center for Bacteria and Fungi Collection of the Iranian Research Organization for Science and Technology. Other high-purity chemicals used in this study were bought from Sigma Incorporation and Merck Company (Darmstadt, Germany).

\subsection{Methods}

\subsubsection{Preparation of the Extract of C. dactylon Rhizome}

(1) Maceration Extraction. For maceration extraction, the rhizomes of $C$. dactylon were ground using a Kenwood CG100 grinder, sieved, and then mixed with methanol at a ratio of $1: 10(\mathrm{wt} / \mathrm{vol})$. The resulting mixture was placed on a hotplate stirrer, at $250 \mathrm{rpm}$, and ambient temperature for $24 \mathrm{~h}$. The mixture was then filtered under vacuum using a Buchner funnel and Whatman filter paper No. 1. To remove the methanol, the mixture was concentrated by a rotary evaporator (LABOROTA 4000 ) at $35^{\circ} \mathrm{C}$, and the extract was eventually dried under vacuum in a drier at $40^{\circ} \mathrm{C}$ and kept in a closed impermeable container at $4^{\circ} \mathrm{C}$ until further use [16].

(2) Microwave-Assisted Extraction. After mixing the plant powder with methanol $(1: 10 \mathrm{wt} / \mathrm{v})$, the sample was soaked in methanol for $60 \mathrm{~min}$. For better extraction, the resulting mixture was irradiated using a microwave oven for 2,4 , and $6 \mathrm{~min}$ at a constant $150 \mathrm{~W}$ power. The mixture was then filtered under vacuum using a Buchner funnel and Whatman filter paper No. 1. To remove the methanol, the mixture was concentrated by a rotary evaporator (LABOROTA 4000) at $35^{\circ} \mathrm{C}$, and the extract was eventually dried under vacuum in a drier at $40^{\circ} \mathrm{C}$ and kept in a closed impermeable container at $4^{\circ} \mathrm{C}$ until further use [17].

(3) Ultrasound-Assisted Extraction. The plant powder was mixed with the methanol solvent $(1: 10 \mathrm{wt} / \mathrm{v})$ and extraction was performed in an ultrasonic bath (Elma) at $80 \mathrm{kHz}$ for 10 , 15 , and $20 \mathrm{~min}$. The mixture was then filtered under vacuum using a Buchner funnel and Whatman filter paper No. 1. To remove the methanol, the mixture was concentrated by a rotary evaporator (LABOROTA 4000 ) at $35^{\circ} \mathrm{C}$, and the 
extract was eventually dried under vacuum in a drier at $40^{\circ} \mathrm{C}$ and kept in a closed impermeable container at $4^{\circ} \mathrm{C}$ until further use [18].

\subsection{Experiments}

2.3.1. Identification of the Chemicals in the Extract. The fatty acid profile of the sample was determined by gas-liquid chromatography (GLC) and reported based on relative percentages for levels [19]. Tocopherol compounds were determined by high-performance liquid chromatography (HPLC, Yang Lin Co.) and sterol levels in the samples were measured by gas chromatography (GC) [19]. In addition, phenolic components were identified by using GC-MS and through comparing retention times of compounds with the Wiley 299, Nist 107, and Nist 21 Libraries.

2.3.2. Oxidative Stability Index. Oxidative stability index was calculated from the following equation based on the concentration of $\mathrm{C}_{18}$ unsaturated fatty acids:

$$
\text { Cox. value }=\frac{\left[1\left(C_{18: 1} \%\right)+10.3\left(C_{18: 2} \%\right)+21.6\left(C_{18: 3} \%\right)\right]}{100} .
$$

Here, $\mathrm{C}_{18: 1}, \mathrm{C}_{18: 2}$, and $\mathrm{C}_{18: 3}$ represent oleic, linoleic, and linolenic acids, respectively [19].

2.3.3. Total Phenolic Content. Total phenolic content of the extract was measured using Folin-Ciocalteu reagent. For this purpose, $2.5 \mathrm{~mL}$ of $0.2 \mathrm{~N}$ Folin-Ciocalteu reagent was added to $0.5 \mathrm{~mL}$ of each extract $(10 \mathrm{mg} / \mathrm{mL})$ and $2 \mathrm{~mL}$ of $75 \mathrm{~g} / \mathrm{L}$ sodium carbonate solution was then added after $5 \mathrm{~min}$. Absorbance by the mixture was read against the blank solution at $760 \mathrm{~nm}$ after $2 \mathrm{~h}$. Gallic acid was used as a standard to plot the calibration curve. The total phenolic content was reported in terms of $\mathrm{mg}$ gallic acid/g extract. The experiments were performed in triplicate and the average was reported [20].

2.3.4. Free Radical (DPPH) Scavenging Activity. The stable radical compound 2,2-diphenyl-1-picryl-hydrazyl-hydrate (DPPH) was used to evaluate the free radical scavenging activity of the methanolic extract of Cynodon dactylon rhizomes. The ability to donate hydrogen atoms or electrons by the different compounds in the extract was evaluated by the discoloration rate or reduction in absorbance by the purple DPPH solution in methanol. Two milliliters of each extract concentration was added to $2 \mathrm{~mL}$ of $0.004 \% \mathrm{DPPH}$ solution in methanol. After $90 \mathrm{~min}$ of storage in the dark at room temperature, absorbance by the sample at $517 \mathrm{~nm}$ was read against the control. The free radical (DPPH) scavenging activity was calculated using the following equation [21]:

$$
I \%=\frac{A_{\text {blank }}-A_{\text {sample }}}{A_{\text {blank }}} \times 100 .
$$

Here, $\mathrm{A}_{\text {blank }}$ and $\mathrm{A}_{\text {sample }}$ represent absorbance by the extractfree control and the extract, respectively. For the comparison, $100 \mathrm{ppm}$ concentration of the synthetic antioxidant butylhydroxyanisole (BHA) was used for comparison.

2.3.5. Antimicrobial Properties of the Extract. A syringe filter with the pore diameter of $0.45 \mu \mathrm{m}$ was used to sterilize the extract. The extract was obtained from the rhizomes of Cynodon dactylon at different concentrations (200, 600, and $1000 \mathrm{ppm}$ ), and the controls were separately prepared in methanol. A fresh culture of each microorganism was required to prepare the microbial suspensions. Therefore, $24 \mathrm{~h}$ prior to the test, the inclined nutrient agar was inoculated with the microorganisms from the stored cultures. The culture was then washed with Ringer's solution to prepare the microbial suspension. A small volume of the microbial solution was poured into a tube containing sterile Ringer's solution and its turbidity was measured by a spectrophotometer at $530 \mathrm{~nm}$. The solution was diluted by Ringer's solution until the turbidity reaches 0.5 of McFarland standard. The resulting suspension needed to contain $1.5 \times 10^{8} \mathrm{CFU} / \mathrm{mL}$ of bacteria. Antimicrobial activity of the methanolic extract of $C$. dactylon was evaluated using agar disk-diffusion method. To this end, one loop of the standard culture of each strain was cultured on a sterile Mueller-Hinton agar medium. Paper discs (diameter of $6 \mathrm{~mm}$ ) sterilized in an autoclave at $121^{\circ} \mathrm{C}$ for $15 \mathrm{~min}$ were impregnated by different concentrations of the methanolic extract of C. dactylon. They were then placed on the surface of culture medium using sterile forceps and fixed with a little pressure on the culture medium. It is noteworthy that antimicrobial activity of the standard gentamicin disks $(10 \mu \mathrm{g} /$ disc) was separately evaluated in Petri dishes. After incubation for $24 \mathrm{~h}$ at $37^{\circ} \mathrm{C}$, the diameter of the nongrowth halo was measured using a caliper (INSTAR, China) with a precision of $0.01 \mathrm{~mm}$. All experiments were performed in triplicate [22].

2.4. Statistical Analysis. A completely randomized statistical design was used to analyze the results. The data were statistically analyzed on SAS. Comparison of the means with each other and the control was carried out using Duncan's test at a probability level of $5 \%(p<0.05)$. Diagrams were plotted in Microsoft Excel 2010.

\section{Results and Discussion}

3.1. The Effects of Extraction Method on Extraction Yield. Three extraction methods, using methanol as solvent, were used in this study to extract the active ingredients in the rhizomes of $C$. dactylon including ultrasound-assisted extraction, microwave-assisted extraction at constant power and different times, and maceration for $24 \mathrm{~h}$. According to the results, the different extraction methods had different yields so that the maceration and the $10 \mathrm{~min}$ ultrasound extraction showed the highest and lowest extraction yields of 10.9 and $2.89 \%$, respectively (Figure 1). The results indicated that extraction yield improved with the increase of time in both microwave- and ultrasound-assisted extraction 


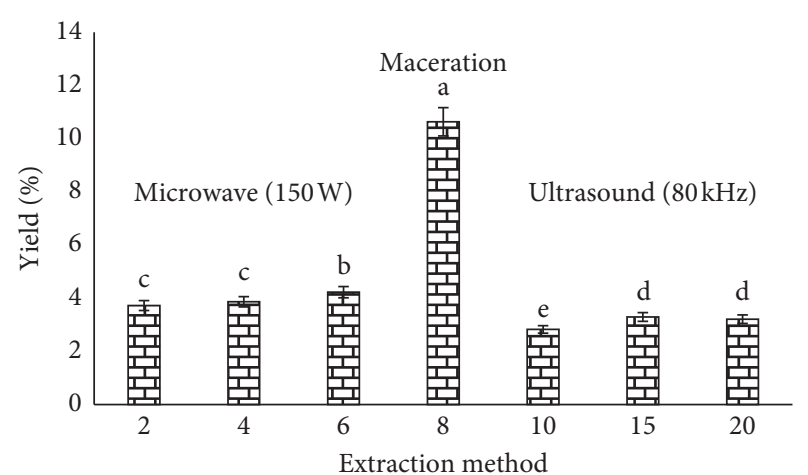

Figure 1: Effects of different methods on extraction yield of $C$. dactylon rhizomes (different letters indicate statistically significant differences between groups as determined by the Duncan test $(p<0.05))$.

methods. By increasing the time from 10 to $20 \mathrm{~min}$ in the ultrasound-assisted extraction, the yield improved from 2.89 to $3.29 \%$. Furthermore, the yield of the microwave-assisted extraction improved from $3.81 \%$ in $2 \mathrm{~min}$ to $4.33 \%$ in $6 \mathrm{~min}$. These observed differences were statistically significant $(p<0.05)$.

Plants contain many compounds with different structures. Extraction of these components depends on multiple factors and the most important of which are the solvent and the extraction method. Selection of the solvent and the extraction method depend on the different parts of the plant and their constituent materials. It is very difficult to select a certain solvent for each class of plant compounds because there are other substances along with these compounds that affect the solubility of the compounds of interest [23]. It should be noted that a high extraction yield for an extract does not necessarily mean a high content of active ingredients. According to the literature, despite the higher yield of an extraction method than another one, the contents of the extracted active ingredients such as phenolic compounds may be lower in the extract with the higher yield [4].

Traditionally, maceration is used for extraction of plant materials. There are numerous studies on the use of maceration to extract various plant compounds including antioxidants. For example, Hypericum perforatum L. extract obtained by maceration shows a good antioxidant activity [24]. Antioxidant activity of corn silk [25], Diospyros lotus, Pyrus boissieriana, and Leontodon hispidus extracted by maceration has also been reported [26]. There are reports of numerous pharmacological effects of the methanolic extract of Juglans regia L. obtained by maceration extraction [27]. There are also reports on the antioxidant activity of the aerial parts of Allium paradoxum and Ferula gummosa Boiss extracted by maceration $[27,28]$. All these studies indicate the good performance of this classic extraction method. Many studies have also been conducted to compare different extraction methods and their yields for extracting active ingredients. These studies indicate that there are insignificant differences between the extraction methods. For example, Soxhlet, ultrasound, and maceration methods were used for extracting Cucumis melo leaves. The results showed that the phenolic content of the extract obtained by Soxhlet extraction was higher. The extract obtained by the Soxhlet method also showed the highest iron chelating activity. All three extraction methods were effective in extracting antioxidant compounds without any significant differences between them [28]. Similar results were obtained regarding the antioxidant activity of Vicia faba so that all three extraction methods effectively extracted antioxidant compounds without any significant differences between them [29].

\subsection{Chemicals Found in the Methanolic Extract of C. dactylon Rhizomes}

3.2.1. Structure of Fatty Acids. Table 1 lists the chemical structures of the fatty acids in the methanolic extract of $C$. dactylon rhizomes extracted by maceration. Clearly, the major fatty acids in the methanolic extract of $C$. dactylon rhizomes were saturated fatty acids including palmitic acid $\left(\mathrm{C}_{16: 0} ; 40.36 \%\right)$ and stearic acid $\left(\mathrm{C}_{18: 0} ; 4.10 \%\right)$ and the unsaturated fatty acids including oleic acid (28.26) and linoleic acid (17.01). The levels of saturated and unsaturated fatty acids in the methanolic extract of $C$. dactylon rhizomes were almost the same. Saturated fatty acids (SFAs), monounsaturated fatty acids (MUFAs), and polyunsaturated fatty acids (PUFAs) comprised $47.39,28.98$, and $21.87 \%$ of the total fatty acids, respectively (Table 1).

The PUFA/SFA ratio of 1.073 was obtained for the methanolic extract of $C$. dactylon rhizomes. This ratio is considered as a measure of unsaturated oils and fats and their tendency for autoxidation of lipids [30]. Therefore, comparison of the oxidative stability index of 3.05 for the extract with the PUFA/SFA ratio indicates a good agreement between these two oxidation indices. According to these oxidation indices, the methanolic extract of $C$. dactylon has a good resistance to oxidation.

3.2.2. Tocopherol Compounds. Tocopherols are a very important nonsoap part of plant extracts and oils. Because of the antioxidant activity of tocopherols, these naturally occurring compounds in plant essential oils are extremely valuable for human health. They protect fats and oils against degradation through reaction with free radicals and directing oxidation reactions to their end stages. This makes tocopherols very valuable for human health [31].

According to the results, the total tocopherol content in the methanolic extract of $C$. dactylon rhizomes was $279.47 \mathrm{mg} / \mathrm{kg}$ with $\alpha$-tocopherol accounting for the largest part $(151.39 \mathrm{mg} / \mathrm{kg})$. Levels of both $\gamma$ - and $\beta$-tocopherol were $128.08 \mathrm{mg} / \mathrm{kg}$; however, $\Delta$-tocopherol was not detected (Table 2). Therefore, one can conclude that the methanolic extract of $C$. dactylon rhizomes is a valuable tocopherol source that can be used in food and pharmaceutical industries.

3.2.3. Evaluation of Sterol Compounds. Plant sterols, also known as phytosterols, comprise more than $50 \%$ of nonsoap 
TABLE 1: Fatty acid profiles of the methanolic extract of C. dactylon rhizomes.

\begin{tabular}{lc}
\hline Fatty acid & Level (\%) \\
\hline$\left(\mathrm{C}_{12: 0}\right)$ Lauric acid & 0.20 \\
$\left(\mathrm{C}_{14: 0}\right)$ Myristic acid & 0.93 \\
$\left(\mathrm{C}_{15: 0}\right)$ Pentadecanoic acid & 0.17 \\
$\left(\mathrm{C}_{16: 0}\right)$ Palmitic acid & 40.36 \\
$\left(\mathrm{C}_{16: 1}\right)$ Palmitoleic acid & 0.37 \\
$\left(\mathrm{C}_{17: 0}\right)$ Margaric acid & 0.21 \\
$\left(\mathrm{C}_{18: 0}\right)$ Stearic acid & 4.10 \\
$\left(\mathrm{C}_{18: 1 t}\right)$ Oleic acid & 0.13 \\
$\left(\mathrm{C}_{18: 1 c}\right)$ Oleic acid & 28.26 \\
$\left(\mathrm{C}_{18: 2 t}\right)$ Linoleic acid & 0.28 \\
$\left(\mathrm{C}_{18: 2 c}\right)$ Linoleic acid & 17.01 \\
$\left(\mathrm{C}_{18: 3}\right)$ Linolenic acid & 4.58 \\
$\left(\mathrm{C}_{20: 0}\right)$ Arachidonic acid & 0.64 \\
$\left(\mathrm{C}_{20: 1}\right)$ Paulinic acid & 0.19 \\
$\left(\mathrm{C}_{22: 0}\right)$ Behenic acid & 0.40 \\
$\left(\mathrm{C}_{24: 0}\right)$ Lignoceric acid & 0.38 \\
Other fatty acids & 1.13 \\
Saturated fatty acids (SFAs) & 47.39 \\
Monounsaturated fatty acids (MUFAs) & 28.98 \\
Polyunsaturated fatty acids (PUFAs) & 21.87 \\
PUFA/SFA & 1.073 \\
Oxidative stability index & 3.05 \\
\hline
\end{tabular}

compounds. Plant sterols are triterpenoids and more than one hundred different types of them have been identified in nature. These metabolites are found in all plant tissues; however, they exist with a higher frequency in seeds [32]. Phytosterols have antioxidant, antibacterial, anti-inflammatory, and wound-healing properties [33]. According to the instrumental results, five sterol compounds with a total content of $9866.24 \mathrm{mg} / \mathrm{kg}$ were identified in the methanolic extract of $C$. dactylon rhizomes. Beta-sitosterol, stigmasterol, and campesterol comprise $3199.62 \mathrm{mg} / \mathrm{kg}$ (32.43\% of total sterol content), $2325.47 \mathrm{mg} / \mathrm{kg}$ (23.57\%), and $2023.56 \mathrm{mg} / \mathrm{kg}$ (20.51\%) of the total sterols, respectively. Among the identified sterols, the lowest sterol content of $460.75 \mathrm{mg} / \mathrm{kg}$ (4.67\%) was that of brassicasterol (Table 3).

Sterols are lipophilic components of the membrane playing a key role in its fluidity. They are necessary for various cell functions. They also have extensive biological activities including anti-inflammatory, anticancer, antioxidant, and antibacterial activities. Moreover, these metabolites are able to reduce blood serum cholesterol level [34]. Therefore, $C$. dactylon seeds can be considered as rich sources of medicinal sterols and a good alternative to cholesterols in food diet. According to the Mangathayaru et al. (2009) reports, C. dactylon steroid saponins have some biological and pharmacological activities, including antibacterial, diuretic, and hypocholesteremic characteristics. It was also found that the fresh juice of $C$. dactylon has immunomodulatory and DNA-protective activity [33].

3.2.4. Identification and Measurement of Phenolic Compounds. Nowadays, phenolic compounds in plants are considered as one of the best natural antioxidant sources. Phenolic compounds form a special group of secondary
TABLE 2: Tocopherol compounds in the methanolic extract of $C$. dactylon rhizomes.

\begin{tabular}{lc}
\hline Tocopherol compounds & Level $(\mathrm{mg} / \mathrm{kg})$ \\
\hline$\alpha$-Tocopherol & 151.39 \\
$\gamma$ - and $\beta$-tocopherol & 128.08 \\
$\Delta$-Tocopherol & $\mathrm{ND}$ \\
Total & 279.47 \\
\hline
\end{tabular}

TABLE 3: Sterol compounds in the methanolic extract of C. dactylon rhizomes.

\begin{tabular}{lcc}
\hline Sterol compounds & $(\mathrm{mg} / \mathrm{kg})$ & Percentage \\
\hline Campesterol & 2023.56 & 20.51 \\
Stigmasterol & 2325.47 & 23.57 \\
Brassicasterol & 460.75 & 4.67 \\
Beta-sitosterol & 3199.62 & 32.43 \\
$\Delta^{5}$ Avenasterol & - & $\mathrm{ND}$ \\
$\Delta^{7}$ Stigmasterol & 1857.81 & 18.83 \\
$\Delta^{7}$ Avenasterol & - & $\mathrm{ND}$ \\
Total sterol compounds & 9866.24 & - \\
\hline
\end{tabular}

ND: nondetectable.

metabolites that play a key role in the protection of tissues against oxidation effects of free radicals, oxygen, and other active species. Thereby, they prevent the occurrence of numerous diseases such as inflammatory diseases, cancer, diabetes, myocardial infarction, and Alzheimer's and Parkinson's diseases [2]. Given the direct relationship between antioxidant effects and levels of phenolic compounds, it seems necessary to identify and measure phenolic compounds in the methanolic extract of $C$. dactylon rhizomes. Phenolic compounds in the methanolic extract were identified by GC/MS, and their relationship with changes in the extract concentration in terms of $\mathrm{mg}$ gallic acid/g extract is shown in Table 4 and Figure 2, respectively. According to the instrumental results, 17 chemicals with hydroxyl groups were identified. Among them, hydroquinone was the most abundant phenolic compound (66.89\%) with two $\mathrm{OH}$ groups in $\mathrm{C}_{1}$ and $\mathrm{C}_{4}$ positions of the aromatic ring. The other notable phenolic compounds were thymol (1.23\%), levoglucosenone $(2.48 \%)$, phytol (1.12\%), vanillic acid (1.35\%), and syringic acid $(0.98 \%)$ (Table 4$)$.

In a similar study, Jananie et al. [35] analyzed the chemicals in the aqueous extract of C. dactylon leaves. Among the identified compounds, glycerine (38.49\%) and phytol (4.89\%) were the major and minor phenolic compounds, respectively [35]. In another study, Kumar and Chandel [11] analyzed C. dactylon leaf extract and identified 24 chemicals. The main compounds were glycerine (38.5\%), thymol (1.15\%), ethyl glucopyranoside (8.42\%), and phytol (4.5\%) [11]. Various factors affect the levels and types of phenolic compounds in plant tissues including genetic factors, solar radiation, soil conditions, stage of maturity at harvest time, weather and environmental conditions, postharvesting operation, and storage conditions [36]. According to the literature on extraction of phenolic compounds from plant tissues, an increase in the extraction temperature significantly increases extraction yield of 
Table 4: Phenolic compounds identified in the methanolic extract of C. dactylon rhizomes.

\begin{tabular}{|c|c|c|c|}
\hline Phenolic compound & Molecular formula & Retention time (min) & Level (\%) \\
\hline Propanoic acid, 2-oxo- & $\mathrm{C}_{3} \mathrm{H}_{4} \mathrm{O}_{3}$ & 3.79 & 1.42 \\
\hline Thymol & $\mathrm{C}_{10} \mathrm{H}_{14} \mathrm{O}$ & 5.54 & 1.23 \\
\hline Pantolactone & $\mathrm{C}_{6} \mathrm{H}_{10} \mathrm{O}_{3}$ & 9.84 & 0.83 \\
\hline 2-Furancarboxaldehyde, 5-methyl- & $\mathrm{C}_{6} \mathrm{H}_{6} \mathrm{O}_{2}$ & 7.75 & 1.55 \\
\hline Pentanoic acid, 4-oxo- & $\mathrm{C}_{5} \mathrm{H}_{8} \mathrm{O}_{3}$ & 9.97 & 0.75 \\
\hline Levoglucosenone & $\mathrm{C}_{6} \mathrm{H}_{6} \mathrm{O}_{3}$ & 12.07 & 2.48 \\
\hline 3-Hydroxy-1-methylpyridinium hydroxide & $\mathrm{C}_{6} \mathrm{H}_{9} \mathrm{NO}_{2}$ & 13.77 & 1.62 \\
\hline Phytol & $\mathrm{C}_{20} \mathrm{H}_{40} \mathrm{O}$ & 15.28 & 1.12 \\
\hline Propanedioic acid, phenyl- & $\mathrm{C}_{9} \mathrm{H}_{8} \mathrm{O}_{4}$ & 15.48 & 1.28 \\
\hline Hydroquinone & $\mathrm{C}_{6} \mathrm{H}_{6} \mathrm{O}_{2}$ & 16.04 & 66.89 \\
\hline 1,3-Benzenediol, 5-chloro- & $\mathrm{C}_{6} \mathrm{H}_{5} \mathrm{ClO}_{2}$ & 17.41 & 1.22 \\
\hline Benzaldehyde, 3-(chloromethyl)-4-methoxy- & $\mathrm{C}_{10} \mathrm{H}_{9} \mathrm{ClO}_{4}$ & 18.63 & 0.85 \\
\hline Ethanone, 1-(4-hydroxy-3-methoxyphenyl)- & $\mathrm{C}_{9} \mathrm{H}_{10} \mathrm{O}_{3}$ & 20.15 & 0.52 \\
\hline 1,6-Anhydro-á-d-glucopyranose (levoglucosan) & $\mathrm{C}_{6} \mathrm{H}_{10} \mathrm{O}_{5}$ & 20.29 & 1.05 \\
\hline Vanillic acid & $\mathrm{C}_{8} \mathrm{H}_{8} \mathrm{O}_{4}$ & 21.30 & 1.35 \\
\hline Syringic acid & $\mathrm{C}_{9} \mathrm{H}_{10} \mathrm{O}_{5}$ & 24.94 & 0.98 \\
\hline Dimethoxybicyclo[3.3.1]nona-2,4-dione & $\mathrm{C}_{11} \mathrm{H}_{16} \mathrm{O}_{4}$ & 26.97 & 0.92 \\
\hline
\end{tabular}

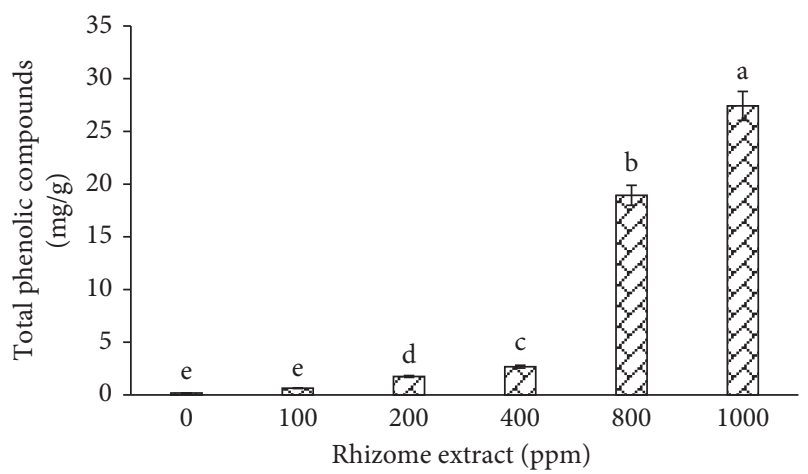

FIGURE 2: Total phenolic compounds at different concentrations of the methanolic extract of $C$. dactylon rhizomes (different letters indicate statistically significant differences between groups as determined by the Duncan test $(p<0.05))$.

phenolic compounds as higher temperature softens plant tissues and weakens interactions between phenolic compounds, proteins, and polysaccharides (and consequently removes more phenolic compounds from the plant to the solvent) [37].

The total phenolic content in the methanolic extract of $C$. dactylon rhizomes was $917.08 \mathrm{mg} / \mathrm{g}$ extract. As seen in Figure 2, when the extract concentration rises from 100 to $1000 \mathrm{ppm}$, the level of phenolic compounds in the extract increases from 0.64 to $27.42 \mathrm{mg}$ gallic acid/g extract. The observed increases were significant at the probability level of $95 \%$ for all extract concentrations compared to control with $0.18 \mathrm{mg}$ gallic acid/g extract $(p<0.05)$. This shows the strong dependence of phenolic compounds in the methanolic extract of $C$. dactylon rhizomes on the concentration so that the level of phenolic compounds significantly improved with increases in extract concentration (Figure 3 ) and led to improved antioxidant properties.

According to the literature, the high level of phenolic compounds is the main reason for the enhanced antioxidant activity of some of the extracts including polar extracts.

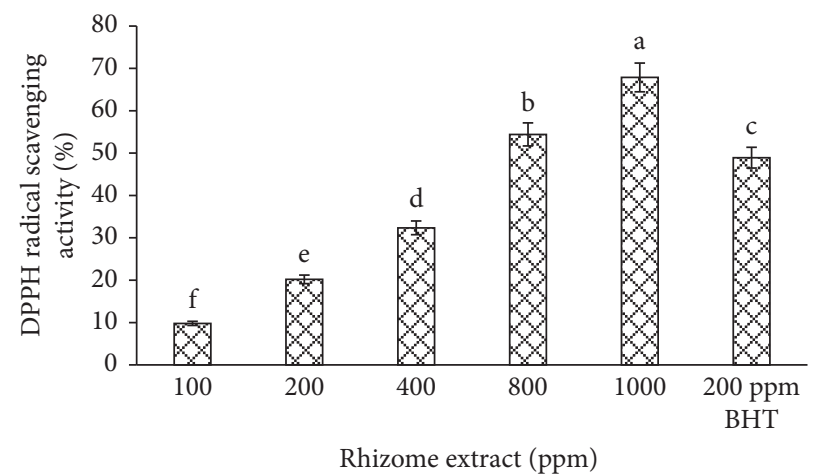

FIGURE 3: Scavenging activity of free radicals by different concentrations of the methanolic extract of $C$. dactylon rhizomes in comparison with the synthetic antioxidant BHT (different letters indicate statistically significant differences between groups as determined by the Duncan test $(p<0.05))$.

Evidences show that there is a positive correlation between the level of phenolic compounds and antioxidant activity of plants. Moreover, it seems that phenolic compounds that are found abundantly in plants with high antioxidant activity can be extracted mainly through plant extracts [38]. The key role of phenolic compounds as free radical scavengers has been reported in several papers $[39,40]$. It is noteworthy that phenolic compounds effectively act as hydrogen donors and thereby as an effective antioxidant. Unver et al. [41] examined the antioxidant activity and total phenol content of methanolic extracts of some plants and found a direct relationship between the total phenol content and antioxidant activity of plant extracts [41]. This is consistent with our results.

3.2.5. Free Radical (DPPH) Scavenging Activity. The activity of the stable DPPH radical is used to evaluate free radical scavenging activity in different samples. The DPPH is a violet stable hydrophilic free radical with the highest absorbance at 515-517 $\mathrm{nm}$. When receiving electrons from reducing 
compounds such as phenols, DPPH is converted into the colorless compound hydrazine. This structural change is associated with reduced absorbance. Compounds with such capability are considered antioxidants [42]. Figure $3 \mathrm{com}$ pares the scavenging activity of different concentrations of the methanolic extract of $C$. dactylon rhizomes with that of $200 \mathrm{ppm}$ of the synthetic antioxidant BHT measured by DPPH. Clearly, the free radical scavenging activity significantly improves with increasing concentrations of the methanolic extract of $C$. dactylon rhizomes. The scavenging activity at $100 \mathrm{ppm}$ was $9.81 \%$ and improved to 67.87 as the extract concentration increased to $1000 \mathrm{ppm}$. The scavenging activity of the methanolic extract of $C$. dactylon rhizomes at 200, 400, and $800 \mathrm{ppm}$ was $20.2,32.36$, and $54.42 \%$, respectively.

By adding $200 \mathrm{ppm}$ of the synthetic antioxidant and comparing its scavenging activity with different concentrations of the methanolic extract of C. dactylon, it was found that $200 \mathrm{ppm}$ of the synthetic antioxidant BHT had a lower scavenging activity (48.93\%) than that of 800 and $1000 \mathrm{ppm}$ methanolic extract of $C$. dactylon rhizomes $(p<0.05)$. This indicates the high scavenging activity of the methanolic extract of $C$. dactylon rhizomes, especially at higher concentrations. The level of this parameter was consistent with that of phenolic compounds in the methanolic extract of $C$. dactylon rhizomes. These results indicate that the phenolic compounds may be responsible for antioxidant activity of the plant extract. The antioxidant potential of the phenolic compounds in plant extracts depends on their type and concentration as well as the number and position of hydroxyl groups in the aromatic ring. An increase in the concentration of phenolic compounds directly increases the ability of different extracts in scavenging free radicals. Due to an increase in the number of hydroxyl groups in the reaction medium at higher concentrations of phenolic compounds, the likelihood of hydrogen donation to free radicals and thereby scavenging activity of the extract increases [43]. Furthermore, these phenolic compounds are converted to phenoxyl free radicals after donating hydrogen. The stability of these radicals may affect antioxidant capacity of phenolic compounds as less-stability phenoxyl radicals compete with DPPH radicals for absorbing hydrogen atoms, which leads to a decrease in the entrapment of DPPH radicals [40].

The antioxidant activity of hydroalcoholic extract of the aerial parts of $C$. dactylon was evaluated by different methods (DPPH radicals scavenging activity, superoxide anion radical scavenging, nitric oxide scavenging, iron chelating capacity, hydroxyl radical scavenging, and hydrogen peroxide scavenging activity). In all these methods, the extract showed a concentration-dependent scavenging activity for free radicals. Determination of superoxide anion radicals showed a maximum antioxidant activity of $93.33 \%$ [44]. In another study, C. dactylon extract was continuously extracted with hexane, ethyl acetate, and methanol. The extract was then concentrated and its antioxidant activity was tested on four cancer cell lines and a normal cell line by DPPH, nitric oxide, and 3-(4,5-dimethylthiazol-2-yl)-2,5-diphenyl tetrazolium bromide (MTT). The anticancer potential of the cytotoxic extract was determined by using Annexin-fluorescein isothiocyanate-conjugated assay in human colon adenocarcinoma cell lines (COLO $320 \mathrm{DM})$. The results showed significant antioxidant and antiproliferative activities of Cynodon dactylon extracts [12].

3.2.6. Antibacterial Effects of the Methanolic Extract of C. dactylon Rhizomes. The spread of drug-resistant and antibiotic-resistant microbial strains is among major problems in the food and drug industries. Medicinal plants have recently received a great deal of attention from researchers for the treatment of acute diseases due to toxic and carcinogenic properties of chemical and synthetic compounds. Accordingly, natural antimicrobial and antioxidant compounds such as organic acids, essential oils, and plant extracts can be considered as good and safe alternatives in foods [44]. In this research, the antimicrobial effects of the methanolic extract of $C$. dactylon native to Iran were evaluated for the first time. To this end, multiple strains of Gram-positive bacteria $(B$. cereus), Gram-negative bacteria (P. aeruginosa, E. coli), and a fungus ( $A$. niger) were selected to determine the effects of different extract concentrations (200,400, and $1000 \mathrm{ppm}$ ) on the nongrowth of these microorganisms using the diskdiffusion method and nongrowth halo diameter (in $\mathrm{mm}$ ). Afterwards, these effects were compared with that of gentamicin as a standard antibiotic (Table 5).

All the concentrations of methanolic extract of $C$. dactylon were effective in preventing the growth of both Grampositive and Gram-negative bacteria and formation of the nongrowth halo. The antioxidant activity of the extract increased with an increase in the extract concentration, which was due to an increase in the phytochemical compounds in the extract. The Gram-positive bacterium $B$. cereus was more sensitive to the extract (a maximum nongrowth halo diameter of $18.3 \pm 0.4 \mathrm{~mm}$ ), whereas the Gram-negative bacterium $P$. aeruginosa showed the highest resistance to the extract with a nongrowth halo diameter of $22.6 \pm 0.28 \mathrm{~mm}$. The extract showed the least effect on $P$. aeruginosa so that no halo was formed around the disk. The methanolic extract of the $C$. dactylon rhizomes with a concentration of $200 \mathrm{ppm}$ had no impact on A. niger; still, a halo with a diameter of $14.4 \pm 0.45 \mathrm{~mm}$ was formed as the extract concentration increased to $1000 \mathrm{ppm}$. However, this was significantly lower than the effect of gentamicin (Table 5). Among the studied microorganisms, extract-free pure methanol (negative control) did not affect $P$. aeruginosa and A. niger; however, a non-growth halo with a diameter of $3.41 \pm 0.18,1.8 \pm 0.08$ and $2.3 \pm 0.1 \mathrm{~mm}$ was formed for $E$. coli, B. cereus, and S. epidermidis, respectively, which was significantly lower than those of the treatments containing the methanolic extract of $C$. dactylon rhizomes and gentamicin.

Hydrophobicity is an important property of plant extracts which enables them to rupture cell membrane and remove vital molecules and ions of bacteria out of the cells and ultimately kill bacteria by forming bonds to the lipid layer of the cell membrane of bacteria and mitochondria [14]. In a similar study, the antibacterial activity of hydroalcoholic extract of Cynodon dactylon against two 
TABLE 5: Inhibitory activity of the methanolic extract of $C$. dactylon rhizome on the growth of microorganisms.

\begin{tabular}{lccccc}
\hline \multicolumn{5}{c}{ Inhabitation zone diameter $(\mathrm{mm})$} \\
\hline A. niger & S. epidermidis & B. cereus & E. coli & P. aeruginosa & Concentration (ppm) \\
$0.00 \pm 0.0^{\mathrm{d}}$ & $2.3 \pm 0.1^{\mathrm{e}}$ & $1.8 \pm 0.08^{\mathrm{e}}$ & $3.34 \pm 0.18^{\mathrm{d}}$ & $0.00 \pm 0.0^{\mathrm{d}}$ & Control $(0)$ \\
$0.00 \pm 0.0^{\mathrm{d}}$ & $9.1 \pm 0.2^{\mathrm{d}}$ & $11.2 \pm 0.15^{\mathrm{d}}$ & $10.25 \pm 0.4^{\mathrm{c}}$ & $7.3 \pm 0.2^{\mathrm{c}}$ & 200 \\
$12.6 \pm 0.3^{\mathrm{c}}$ & $12.5 \pm 0.35^{\mathrm{c}}$ & $14.8 \pm 0.25^{\mathrm{c}}$ & $15.3 \pm 0.3^{\mathrm{ab}}$ & $10.4 \pm 0.3^{\mathrm{b}}$ & 600 \\
$14.4 \pm 0.45^{\mathrm{b}}$ & $15.7 \pm 0.4^{\mathrm{ab}}$ & $18.3 \pm 0.4^{\mathrm{b}}$ & $16.8 \pm 0.5^{\mathrm{a}}$ & $12.8 \pm 0.15^{\mathrm{a}}$ & 1000 \\
$22.6 \pm 0.28^{\mathrm{a}}$ & $17.52 \pm 0.17^{\mathrm{a}}$ & $20.8 \pm 0.5^{\mathrm{a}}$ & $16.1 \pm 0.1^{\mathrm{a}}$ & $0.00 \pm 0.0^{\mathrm{d}}$ & Gentamicin \\
\hline
\end{tabular}

* Different letters indicate statistically significant differences between groups as determined by the Duncan test $(p<0.05)$.

Gram-positive bacteria (S. aureus and S. albus) and two Gram-negative bacteria (E. coli and P. aeruginosa) was evaluated using the disc-diffusion (zone of inhabitation) and the dilution (minimum inhibitory concentration) methods. The results showed that the hydroalcoholic extract of $C$. dactylon had an effective antibacterial activity. The results regarding the minimum inhibitory concentrations indicated the sensitivity of all bacterial strains to $C$. dactylon extract [45]. In another study, the antimicrobial activity of crude $C$. dactylon extracts obtained from seven different solvents (acetone, chloroform, diethyl ether, ethanol, ethyl acetate, and $n$-pentane) against some pathogens was investigated using the disk-diffusion method. The results showed the extensive antimicrobial activity of ethanol $(7-10 \mathrm{~mm})$ and ethyl acetate $(7-12 \mathrm{~mm})$ extracts against all bacterial pathogens. Both methanol and acetone extracts showed a significant antimicrobial activity against $B$. cereus and $B$. subtilis, whereas the chloroform extract showed an antimicrobial activity against $S$. pyogenes. Ethyl acetate and ethanol extracts with inhibition zones of $8-15 \mathrm{~mm}$ and $8-13 \mathrm{~mm}$, respectively, showed a reasonable antimicrobial activity. However, no significant antimicrobial activity was found against $A$. niger [14].

Suresh et al. [46] examined theantibacterial activity of C. dactylon leaf extract against pathogenic bacteria (B. subtilis, S. aureus, E. coli, K. pneumonia, and S. aeruginosa) using the agar disk-diffusion method [46]. According to the results, the chloroform extract of $C$. dactylon leaves showed a significant antibacterial activity against all tested bacteria. The chloroform extract with a concentration of $75 \mu \mathrm{L} / \mathrm{mL}$ formed a larger inhabitation zone than those with concentrations of 25 and $50 \mu \mathrm{L} / \mathrm{mL}$. Most bacteria, however, were resistant to the aqueous extract of $C$. dactylon. In a different in vivo study, the antiviral activity of $C$. dactylon extract produced on a large scale on white spot syndrome virus (WSSV) was investigated in Penaeus monodon. To this end, the C. dactylon extract was mixed with artificial pellet feed with a concentration of 1 or $2 \%$. The results showed the significant effect of C. dactylon extract on prevention of WSSV infection without mortality [47]. In another research, Rahman (2014) by studying the antimicrobial activity of three different extraction of $C$. dactylon against some pathogen bacteria reported that the hot and cold aqueous extracts of this herb had antimicrobial activity against all the test Gram-positive and Gram-negative bacteria indicating broad-spectrum activity of the extract for organisms. While the effect of methanol extract was not significant, this is probably due to the differences in the method of extraction and nonuse of ultrasound in the preparation of methanol extract [5].

According to the results of this research and of those reported in other studies, one can conclude that the methanolic extract of $C$. dactylon rhizomes is able to inhibit the growth of pathogenic and spoilage bacteria in foods. Thus, it is recommended to use it as a natural preservative and flavoring agent in food products.

\section{Conclusion}

Given the growing awareness in consumers of the effects of synthetic antioxidants on public health and the ever-increasing prevalence of drug resistance in bacteria, more attention has been paid to finding ways of preventing drug resistance and also developing effective drugs with less side effects. Medicinal plants such as C. dactylon, which grow in different regions of Iran, have received a great deal of attention in this regard. The results showed that the methanolic extract of C. dactylon rhizomes, especially at higher concentrations, was able to scavenge free radicals. This feature was due to higher levels of antioxidant, tocopherol, and phenolic compounds. The extracts with concentrations of 800 and $1000 \mathrm{ppm}$ showed higher scavenging activity than the extract with concentration of $200 \mathrm{ppm}$ of the synthetic antioxidant BHT. Furthermore, the methanolic extract of $C$. dactylon rhizomes showed a wide range of activities against both Gram-positive and Gram-negative bacteria and against the mold A. niger as well. The antibacterial activity of the methanolic extract of $C$. dactylon arising from phytochemical compounds confirms its application as a therapeutic drug in folk medicine. Therefore, biological compounds that are identified in C. dactylon can be used to produce antimicrobial drugs for the treatment of various diseases such as eye infections, pneumonia, and gonorrhea. The results of this study showed that the methanolic extract of $C$. dactylon rhizomes could be considered an antibacterial agent and a potential source of antibiotics for the treatment of bacterial infections. Due to the high antioxidant activity of this plant extract, it can be used as a good alternative to synthetic antioxidants for preserving food materials and edible oils.

\section{Data Availability}

The data used to support the findings of this study are included within the article. 


\section{Conflicts of Interest}

The authors declare that there are no conflicts of interest with respect to the authorship and/or publication of this article.

\section{Acknowledgments}

The authors thank the management of Islamic Azad University-Neyshabur Branch for their financial support and the director of central lab of the university for the help with the experiments.

\section{References}

[1] S. Andrade, M. J. Ramalho, J. A. Loureiro, and M. D. Pereira, "“Natural compounds for Alzheimer's disease therapy: a systematic review of preclinical and clinical studies," International Journal of Molecular Sciences, vol. 20, p. 41, 2019.

[2] I. F. F. Benzie and S. Wachtel-Galor, Herbal Medicine: Biomolecular and Clinical Aspects, CRC Press/Taylor \& Francis Group, Boca Raton, FL, USA, 2nd edition, 2011.

[3] K. R. R. Rengasamy, H. Khan, S. Gowrishankar et al., "The role of flavonoids in autoimmune diseases: therapeutic updates," Pharmacology \& Therapeutics, vol. 194, pp. 107-131, 2019.

[4] R. Dutt, V. Garg, N. Khatri, and A. K. Madan, "Phytochemicals in anticancer drug development," Anti-Cancer Agents in Medicinal Chemistry, vol. 19, no. 2, pp. 172-183, 2019.

[5] S. Rahman, Cynodon Dactylon: Antimicrobial Potential of Crude Extract as Valuable Medicinal Plant, BRAC University, Bangladesh, India, 2014.

[6] P. D. A. E. Al-Snafi, "A review on chemical constituents and pharmacological activities of Coriandrum sativum," IOSR Journal of Pharmacy (IOSRPHR), vol. 6, no. 7, pp. 17-42, 2016.

[7] A. B. Oyenihi and C. Smith, "Are polyphenol antioxidants at the root of medicinal plant anti-cancer success?" Journal of Ethnopharmacology, vol. 229, pp. 54-72, 2019.

[8] M. Ayaz, F. Ullah, A. Sadiq et al., "Synergistic interactions of phytochemicals with antimicrobial agents: potential strategy to counteract drug resistance," Chemico-Biological Interactions, vol. 308, pp. 294-303, 2019.

[9] P. Maher, "The potential of flavonoids for the treatment of neurodegenerative diseases," International Journal of Molecular Sciences, vol. 20, no. 12, p. 3056, 2019.

[10] D. Venkatachalam, B. S. Thavamani, and K. Muddukrishniah, "Antimicrobial activity and phytochemical analysis of aerial parts of Cynodon dactylon," International Journal of Academic Research and Development, vol. 3, no. 3, pp. 116-121, 2018.

[11] E. Chandel and B. Kumar, "Antimicrobial activity and phytochemical analysis of Cynodon dactylon: a review," World Journal of Pharmacy and Pharmaceutical Sciences, vol. 4, no. 11, pp. 515-530, 2015.

[12] A. Albert-Baskar and S. Ignacimuthu, "Chemopreventive effect of Cynodon dactylon (L.) Pers. extract against DMHinduced colon carcinogenesis in experimental animals," $E x$ perimental and Toxicologic Pathology, vol. 62, no. 4, pp. 423-431, 2010.

[13] P. K. Rai, D. Jaiswal, D. K. Rai, B. Sharma, and G. Watal, "Antioxidant potential of oral feeding ofcynodon dactylonextract on diabetes-induced oxidative stress," Journal of Food Biochemistry, vol. 34, no. 1, pp. 78-92, 2010.
[14] S. Abdullah, J. Gobilik, and K. P. Chong, "In vitro antimicrobial activity of Cynodon dactylon (L.) pers. (bermudas) against selected pathogens," Developments in Sustainable Chemical and Bioprocess Technology, vol. 16, pp. 227-237, 2013.

[15] A. S. Kumar, K. Gnananath, D. Kiran, A. M. Reddy, and C. Raju, "Antidiabetic activity of ethanolic extract of Cynodon dactylon root stalks in streptozotocin induced diabetic rats," International Journal of Advances in Pharmaceutical Research, vol. 2, no. 8, pp. 418-422, 2011.

[16] M. Mazandarani, S. Makri, and G. R. Bajian, "Evaluation of phytochemical and antioxidant activity in different parts of Heracleum gorganicum rech. F. in Golestan Province, North of Iran"' Iranian Journal of Plant Physiology, vol. 2, no. 2, pp. 381-388, 2011.

[17] M. Mirzapour, M. Hamedi, and M. Rahimipanah, "Sunflower oil stabilization by Persian walnut leaves extract during oven storage test," Food Science and Technology Research, vol. 16, no. 5, pp. 443-446, 2010.

[18] R. D. Sotillo, M. Hadley, and E. T. Holm, "Phenolics in aqueous potato peel extract: extraction, identification and degradation"” Journal of Food Science, vol. 59, no. 2, pp. 649-651, 1994.

[19] R. Farhoosh, J. Tavakoli, and M. H. H. Khodaparast, "Chemical composition and oxidative stability of kernel oils from two current subspecies of Pistacia atlantica in Iran," Journal of the American Oil Chemists' Society, vol. 85, no. 8, pp. 723-729, 2008.

[20] A. Ordonez, J. Gomez, M. Vattuone, and M. lsla, "Antioxidant activities of Sechium edule (jacq.) swartz extracts," Food Chemistry, vol. 97, no. 3, pp. 452-458, 2006.

[21] A. Dashipour, R. Khaksar, H. Hosseini, S. Shojaee-Aliabadi, and K. Ghanati, "Physical, antioxidant and antimicrobial characteristics of carboxymethyl cellulose edible film cooperated with clove essential oil," Zahedan Journal of Research in Medical Sciences, vol. 16, no. 8, pp. 34-42, 2014.

[22] S. Mohammadi Amlashi and B. Babakhani, "Examining the antibacterial activity of Artemisia dracunculus L. extracts using different methods of extraction," International Journal of Molecular and Clinical Microbiology, vol. 6, no. 1, pp. 629-634, 2016.

[23] S. F. Nabavi, M. A. Ebrahimzadeh, S. M. Nabavi, M. Mahmoudi, and S. K. Rad, "Biological activities of Juglans regia flowers," Revista Brasileira de Farmacognosia, vol. 21, no. 3, pp. 465-470, 2011.

[24] H. Fathi, "Antioxidant and free radical scavenging activities of Hypericum perforatum L," International Journal of Forest, Soil and Erosion, vol. 3, no. 2, pp. 68-72, 2013.

[25] M. A. Ebrahimzadeh, F. Pourmorad, and S. Hafezi, "Antioxidant activities of Iranian corn silk," Turkish Journal of Biology, vol. 32, no. 1, pp. 43-49, 2008.

[26] M. A. Ebrahimzadeh, S. Eslami, S. M. Nabavi, S. F. Nabavi, and B. Eslami, "Antioxidant and antihemolytic activities ofLeontodon hispidos," Biotechnology \& Biotechnological Equipment, vol. 24, no. 4, pp. 2127-2131, 2010.

[27] S. M. Nabavi, M. A. Ebrahimzadeh, S. F. Nabavi, B. Eslami, and A. A. Dehpour, "Antioxidant and antihaemolytic activities of Ferula foetida regel (Umbelliferae)," European Review for Medical and Pharmacological Sciences, vol. 15, no. 15, pp. 157-164, 2011.

[28] M. A. Ebrahimzadeh, M. Askari, and M. Forouzani, "Evaluation of three methods for the extraction of antioxidants from Cucumis melo L. fruit and leaves," International Journal of Forest, Soil and Erosion, vol. 3, no. 3, pp. 95-99, 2013. 
[29] Z. Hashemi and M. A. Ebrahimzadeh, "Evaluation of methods for the extraction of antioxidants from Vicia faba L. bean and hulls," Latin American Applied Research, vol. 44, pp. 203-208, 2014.

[30] F. Sahin, M. Gulluce, D. Daferera et al., "Biological activities of the essential oils and methanol extract of Origanum vulgare ssp vulgare in the Eastern Anatolia region of Turkey," Food Control, vol. 15, pp. 549-557, 2004.

[31] R. Swetie, Ch Raesh, and S. Arun, "Antioxidant potential of mint (Mentha Spicata L.) in radiationprocessed lamb meat," Food Chemistry, vol. 100, no. 2, pp. 451-458, 2007.

[32] M. J. Lagarda, G. García-Llatas, and R. Farré, "Analysis of phytosterols in foods," Journal of Pharmaceutical and Biomedical Analysis, vol. 41, no. 5, pp. 1486-1496, 2006.

[33] K. Mangathayaru, M. Umadevi, and C. U. Reddy, "Evaluation of the immunomodulatory and DNA protective activities of the shoots of Cynodon dactylon," Journal of Ethnopharmacology, vol. 123, no. 1, pp. 181-184, 2009.

[34] Y. Boutté and M. Grebe, "Cellular processes relying on sterol function in plants," Current Opinion in Plant Biology, vol. 12, no. 6, pp. 705-713, 2009.

[35] R. K. Jananie, V. Priya, and K. Vijayalakshmi, "Determination of bioactive components of Cynodon dactylon by GC-MS analysis," New York Science Journal, vol. 4, 2011.

[36] S. Khanizadeh, L. Ding, R. Tsao et al., "Phytochemical distribution among selected advanced apple genotypes developed for fresh market and processing," Journal of Food, Agriculture and Environment, vol. 1, no. 2, 2007.

[37] J. Shi, J. Yu, J. Pohorly, J. C. Young, M. Bryan, and Y. Wu, "Optimization of the extraction of polyphenols from grape seed meal by aqueous ethanol solution," Food, Agriculture \& Environment, vol. 1, no. 2, pp. 42-47, 2003.

[38] C. Chatchawan, B. Soottawat, H. Jakul, and S. Nattiga, "Antioxidant components and properties of five long- grained rice bran extracts from commercial available cultivars in Thailands," Food Chemistry, vol. 111, no. 3, pp. 636-641, 2008.

[39] V. Katalinic, M. MIlos, T. Kulisic, and M. Jukic, "Screening of 70 medicinal plant extracts for antioxidant capacity and total phenols," Food Chemistry, vol. 94, no. 4, pp. 550-557, 2006.

[40] M. Thériault, S. Caillet, S. Kermasha, and M. Lacroix, "Antioxidant, antiradical and antimutagenic activities of phenolic compounds present in maple products," Food Chemistry, vol. 98, no. 3, pp. 490-501, 2006.

[41] A. Unver, D. Arslan, M. M. Ozcan, and M. Akbulut, "Phenolic content and antioxidant activity of some spices," World Applied Sciences Journal, vol. 6, pp. 373-377, 2009.

[42] S. Kim, S.-C. Ko, Y.-S. Kim et al., "Determination of Curcuma longa L. (Turmeric) leaf extraction conditions using response surface methodology to optimize extraction yield and antioxidant content," Journal of Food Quality, vol. 2019, pp. 1-8, 2019.

[43] J. Wang, X. Cao, H. Jiang, Y. Qi, K. Chin, and Y. Yue, "Antioxidant activity of leaf extracts from different Hibiscus sabdariffa accessions and simultaneous determination five major antioxidant compounds by LC-Q-TOF-MS," Molecules, vol. 19, no. 12, pp. 21226-21238, 2014.

[44] M. J. Saharkhiz, M. Sattari, Gh.R. Goudarzi, and R. Omidbygy, "The effect of antibacterial herb Tanacetum parthenium L," Journal-Iranian Medicinal and Aromatic Plants Research, vol. 24, pp. 47-55, 2008.

[45] S. Renu and N. B. Prakash, "Screening of antibacterial activity of hydroalcoholic extract of Cynodon dactylon (L.)," International Journal of Research in Ayurveda and Pharmacy, vol. 3, no. 6, pp. 827-829, 2012.
[46] K. Suresh, P. Deepa, R. Harisaranraj, and V. Vaira Achudhan, "Antimicrobial and phytochemical investigation of the leaves of Carica papaya L, Cynodon dactylon L Pers, Euphorbia hirta L, Melia azedarach L and Psidium guajava L," Ethnobotanical Leaflets, vol. 12, pp. 1184-1191, 2008.

[47] A. S. Hameed, G. Balasubramanian, M. Sarathi, C. Venkatesan, and J. Thomas, "Oral administration of antiviral plant extract of Cynodon dactylon on large scale production against white spot syndrome virus (WSSV) in Penaeus monodon," Journal of Aquaculture, vol. 279, pp. 2-5, 2008. 